\title{
Complete biochemical control and pituitary adenoma disappearance in a child with gigantism: Efficacy of octreotide therapy
}

\section{CASE REPORT}

Gigantism is a rare childhood condition due, in most cases, to pituitary $\mathrm{GH}$-secreting adenoma. Only isolated clinical cases are reported in the literature, showing the benefits of both medical and surgical therapy and few data about the management of this disease and the long-standing outcomes of medical treatment are available, without a general consensus. Transnasal pituitary surgery was found to be as safe in pediatric patients with gigantism as in acromegalic adults (1) and, on the other hand, somatostatin analogs seem effective as well as pegvisomant in control of the disease (2-4); however, disappearance of adenoma during primary medical therapy in children was never reported in the literature and the discontinuation of therapy usually results in a recurrence of the disease $(3,5)$. We report the clinical course of a 11.2-yr-old pre-pubertal girl with gigantism due to a $\mathrm{GH}$-producing pituitary adenoma, treated as primary therapy with long-acting octreotide for $3 \mathrm{yr}$, with progressive shrinkage of tumor until its complete disappearance. She was admitted 6 yr ago to our Endocrine Unit because of recent evidence of defluvium capitis, weakness, and weight increase. Her stature was over the $97^{\text {th }}$ percentile $(177 \mathrm{~cm}$ ) concomitant with a reported recent growth spurt (heightvelocity about $20 \mathrm{~cm}$ and weight gain $5 \mathrm{~kg}$ in the last 6 months). At clinical examination she had a Tanner pubertal status PH1B2, seborrheic skin and hair, normal levels of systolic and diastolic blood pressure and heart rate. Basal hormonal evaluation revealed normal thyroid hormones and PRL, elevated IGF-I (718 ng/ml, agematched normal 98-404) and pulsatile GH levels (12-8.6$10 \mathrm{ng} / \mathrm{ml}$ ), with absence of $\mathrm{GH}$ suppression to oral glucose tolerance test (OGTT) (nadir $5.9 \mathrm{ng} / \mathrm{ml}$ ). Glucose tolerance and glycosylated hemoglobin $\left(\mathrm{HbA}_{1 \mathrm{c}}\right)$ levels were normal and gonadotrophins and $17 \beta$-estradiol were consistent with pre-pubertal stage. The patient had a hand-wrist bone age of $13.5 \mathrm{yr}$. A magnetic resonance imaging (MRI) scan showed an intrasellar microadenoma (8 mm) (Fig. 1A). Campimetry and echocardiography showed normal findings. After diagnosing pituitary gigantism, we introduced long-acting release (LAR) octreotide (monthly injections of $20 \mathrm{mg}$ ) to suppress $\mathrm{GH}$ secretion. Immediately, the patient attained fully normalization of GH and IGF-I levels, leading to the normalization of height-velocity. The patient complained of slight nausea only in the first 3 weeks of treatment, without other side effects. In accordance with our standard protocol, the patient underwent liver function test every 3 months and abdominal ultrasound annually, without evidence of any alteration. In addition, she always showed a normal glucose tolerance (NGT) when annually OGTT was performed, with normal glucose, insulin, and $\mathrm{HbA}_{1 \mathrm{c}}$ levels. After the first 3 months of treatment, pulsatile $\mathrm{GH}$ levels were 3.2-3.1-1.1 ng/ml, with concomitant normal IGF-I $(313 \mathrm{ng} / \mathrm{ml})$. After 6 months, MRI revealed a $25 \%$ reduction of the microadenoma size (6 $\mathrm{mm})$, concomitant with IGF-I levels and GH nadir after OGTT in the normal range.

The height-velocity was immediately blocked and puberty regularly began $1 \mathrm{yr}$ after the start of treatment, with menarche at age 13 and subsequent regular menses. After 1 yr of therapy, because of hyper-suppression of serum levels of GH (nadir during OGTT 0.3 $\mathrm{ng} / \mathrm{ml}$ ) with concomitant IGF-I below the normal range

๑2011, Editrice Kurtis

Accepted October 12, 2010

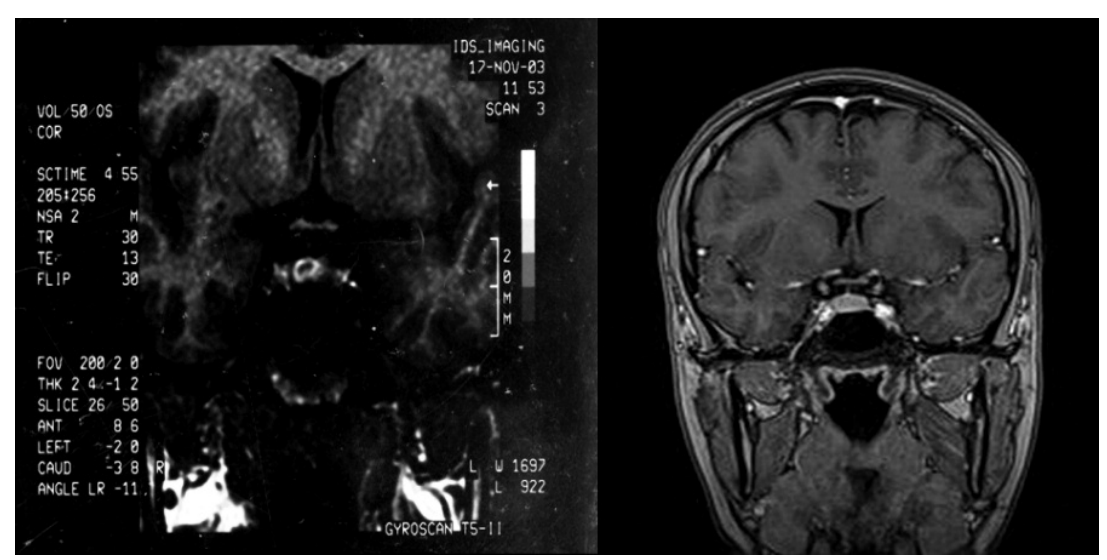

Fig. 1 - A) Magnetic resonance imaging (MRI) at diagnosis showing an intrasellar microadenoma (8 mm). B) MRI during follow-up after 3 yr of octreotide-treatment discontinuation (undetectable adenoma). 
$(91 \mathrm{ng} / \mathrm{ml})$, we reduced the dose of octreotide-LAR to 10 $\mathrm{mg} / \mathrm{month}$. The height-velocity had slowed to $2 \mathrm{~cm} / \mathrm{yr}$, the hand-wrist bone age was $13.9 \mathrm{yr}$ and MRI revealed an additional reduction in microadenoma size $(4.5 \mathrm{~mm}$, $43.7 \%$ of total reduction). After $3 \mathrm{yr}$ of treatment, because of the constant suppressed GH and IGF-I levels, despite the observed residual $3-\mathrm{mm}$ pituitary area $(62.5 \%$ of total reduction), LAR-octreotide was discontinued and the patient being kept in a close follow-up every 6 months. The patient maintained a slow height-velocity $(1-2 \mathrm{~cm} / \mathrm{yr})$, GH and IGF-I values as disease remission and NGT. Disease remission was defined as either nadir levels of $\mathrm{GH}<1$ $\mathrm{ng} / \mathrm{ml}$ during OGTT and normal age-adjusted levels of IGF-I without pituitary suppressive medications. Annual MRI showed a progressive reduction in microadenoma size until its complete disappearance after $3 \mathrm{yr}$ of washout period (Fig. 1B), concomitant with normal hormonal evaluation. A likely explanation of this finding could be that probably the real success of octreotide therapy was mediated by apoptosis of pituitary adenoma, that after a long period of wash-out induced a complete disappearance of the tumor.

This report is a rare case of complete remission of gigantism due to $\mathrm{GH}$-secreting pituitary adenoma during medical treatment. Our experience in this exemplary clinical case suggests the efficacy of LAR-octreotide as primary treatment to reach complete clinical, biochemical, and radiological control of gigantism in children. In addition, the persistence of controlled clinical and biochemical parameters for a long period after octreotide discontinuation, concomitant with progressive shrinkage of pituitary microadenoma until its complete disappearance, suggests the "long-duration" action of octreotide and the potential antitumoral effect of this treatment al- so after its discontinuation, although the mechanism are not yet fully understood.

\section{ACKNOWLEDGMENTS}

The authors wish to thank Prof. Ezio Ghigo for his helpful comments and suggestions in the long-term follow-up.

\section{Disclosure statement}

The Authors have nothing to declare.

\author{
A. Ciresi, M.C. Amato, A. Galluzzo, \\ and C. Giordano \\ Section of Endocrinology, DOSAC (Dipartimento di \\ Oncologia Sperimentale ed Applicazioni Cliniche), \\ University of Palermo, Palermo, Italy
}

\section{REFERENCES}

1. Abe T, Tara LA, Lüdecke DK. Growth hormone-secreting pituitary adenomas in childhood and adolescence: features and results of transnasal surgery. Neurosurgery 1999, 45: 1-10.

2. Bergamaschi S, Ronchi CL, Giavoli C, et al. Eight-year follow-up of a child with a $\mathrm{GH} /$ prolactin-secreting adenoma: efficacy of pegvisomant therapy. Horm Res Paediatr 2010, 73: 74-9.

3. Schoof E, Dörr HG, Kiess W, et al. Five-year follow-up of a 13-yearold boy with a pituitary adenoma causing gigantism--effect of octreotide therapy. Horm Res 2004, 61: 184-9.

4. Goldenberg N, Racine MS, Thomas P, Degnan B, Chandler W, Barkan A. Treatment of pituitary gigantism with the growth hormone receptor antagonist pegvisomant. J Clin Endocrinol Metab 2008, 93: 2953-6.

5. Maheshwari HG, Prezant TR, Herman-Bonert V, Shahinian H, Kovacs K, Melmed S. Long-acting peptidomimergic control of gigantism caused by pituitary acidophilic stem cell adenoma. J Clin Endocrinol Metab 2000, 85: 3409-16. 